\title{
Sorafenib in radioactive iodine-refractory well-differentiated metastatic thyroid cancer
}

\author{
This article was published in the following Dove Press journal: \\ OncoTargets and Therapy \\ 15 July 2014 \\ Number of times this article has been viewed
}

\author{
Daniel C McFarland' \\ Krzysztof J Misiukiewicz ${ }^{2,3}$ \\ 'Division of Hematology and Medical \\ Oncology, Mount Sinai Medical \\ Center, New York, NY, USA; '² Division \\ of Hematology and Medical Oncology, \\ ${ }^{3}$ Department of Otolaryngology, \\ Mount Sinai Medical Center, \\ Ruttenberg Treatment Center, \\ New York, NY, USA
}

\begin{abstract}
Recent Phase III data presented at the American Society of Clinical Oncology (ASCO) 2013 annual conference by Brose et al led to the US Food and Drug Administration (FDA) approval of sorafenib for the treatment of well-differentiated radioactive iodine-resistant metastatic thyroid cancer. This is the second drug in 40 years to be FDA approved for this indication. Recent reviews and a meta-analysis reveal a modest ability to induce a partial remission but substantial ability to halt disease progression. Given the significant activating mutations present in thyroid cancer, many of which are inhibited by sorafenib, the next logical approach may be to combine targeted rational therapies if permitted by collective toxicity profiles. This systematic review aims to summarize the recent Phase II/III data leading to the FDA approval of sorafenib for radioactive iodine therapy differentiated thyroid cancer and highlights recent novel combination therapy trials.
\end{abstract}

Keywords: tyrosine kinase inhibitors, targeted therapy, RAI DTC, novel thyroid cancer treatment

\section{Introduction}

Recent Phase III data presented at the American Society of Clinical Oncology (ASCO) 2013 annual conference by Brose et $\mathrm{al}^{1}$ led to the US Food and Drug Administration (FDA) approval of sorafenib for the treatment of radioactive iodine-resistant (RAI-R) metastatic well-differentiated thyroid cancer (DTC). This is the second drug in 40 years to be FDA approved for this indication. Well-DTC is one of the fastest growing cancers in incidence. ${ }^{2,3}$ Historically, localized thyroid cancers have been treated by surgical resection and adjuvant thyroid ablative therapy which cures approximately $85 \%$ of papillary and follicular subtypes. ${ }^{4}$ Even with distant metastasis, it is still considered an indolent cancer usually until it loses its radioiodide avidity, which happens in roughly $30 \%-50 \%$ of metastatic cases. ${ }^{5}$ At that time, the 5-year survival of a patient with iodine-concentrating pulmonary metastasis goes from $60 \%-80 \%$ to roughly $30 \%$ for those tumors that do not take up iodine. ${ }^{6}$ Prior to November 2013 , only one FDA-approved drug, doxorubicin, was being used to treat these patients but with a response rate of about $5 \%$ according to a recent analysis of modern radiographic images. ${ }^{7}$ Sorafenib was approved for the treatment of well-differentiated thyroid cancer according to several Phase II studies and a Phase III study (Table 1) which have consistently shown the induction of stable disease (SD), and, less frequently, partial response $(\mathrm{PR})$, in the setting of progressive metastatic DTC with predictable side effect profiles that are consistent with sorafenib use in other settings. Clinical testing of tyrosine kinase inhibitors (TKIs) began in the early 2000s and comes from the
Correspondence: Daniel McFarland Division of Hematology and Medical Oncology, Mount Sinai Medical Center, Box 1079, One Gustave Levy Place, New York, NY 10029, USA

Email daniel.mcfarland@mountsinai.org 
rationale basis of testing TKIs in tumors that incur increasing mutations in tyrosine kinase pathways corresponding to dedifferentiation and aggressiveness. ${ }^{3,8}$ The biology of thyroid cancer harbors one of the most fascinating models of carcinogenesis since the two primary signal transduction cascades, the PI3 kinase and MAP kinase pathways, accumulate increasingly activating mutations as they become more dedifferentiated and aggressive. As driver and passenger mutations are increasingly understood, targeted agents, and in particular the TKIs, hold much promise in the treatment of metastatic well-DTC.

Sorafenib (BAY 43-9006) is a small molecule that specifically inhibits Raf kinase, which is a downstream effector that follows from Ras activation. Three isoforms of Raf have been identified, A-Raf, B-Raf, and C-Raf. Sorafenib is unique among clinically used TKIs because it was the first compound capable of inhibiting all RAF kinases. ${ }^{9}$ Additionally, it targets a panel of angiogenic tyrosine kinase receptors such as vascular endothelial growth factor receptors (VEGFR1-3), platelet-derived growth factor receptor $\beta$ (PDGFR $\beta$ ), and rearranged during transfection (RET) receptors. Thus, this agent has proapoptotic, via RAF inhibition, and antiangiogenic properties. These properties are of special interest in thyroid cancer, which generally displays diffuse neovascularization and variable activating mutations in the MAPK or PI3K-AKT pathways. $^{10}$

Treatment for medullary thyroid cancer (MTC) has advanced at a more rapid pace. Two FDA-approved agents and greater Phase III-level evidence are available for the treatment of MTC in the metastatic setting. ${ }^{11,12}$ Although sorafenib has been approved to treat metastatic well-DTC, it is not a panacea and has a noteworthy side effect profile. This systematic review will compile the most recent evidence for the use of sorafenib and rationale for its FDA approval as well as some of the notable side effects and other observational data from recent trials. This review will also review clinical trials that have used sorafenib in combination with other targeted agents, namely the mammalian target of rapamycin (mTOR) inhibitors.

\section{Materials and methods}

\section{Databases included in the search}

Literature searches were conducted utilizing PubMed and Ovid on December 1, 2013. The Embase database includes all MEDLINE records produced by the National Library of Medicine (NLM), as well as more than 5 million records not covered on MEDLINE. The Embase database also encompasses the Cochrane Database of Systematic Reviews (CDSR).

\section{Search strategy}

The free-text terms for the disease "thyroid cancer", "thyroid neoplasm", and "thyroid tumor" were combined with the term "sorafenib" and placed into the PubMed and Ovid search engines on December 1, 2013. Trial-related terms were not required for Cochrane Libraries searches, as the Cochrane databases are divided by study type. Finally, to target studies in an RAI-R population, the clinical trials searches also included free-text terms such as "radio-iodine", "iodine", "refractory", "advanced", "iodine insensitive", and "radioiodine unresponsive".

\section{Study inclusion and exclusion criteria}

The review was restricted to peer-reviewed studies involving human research in the English language and published in the year 2000 or later, as many studies prior to 2000 involved the use of doxorubicin. Inclusionary criteria also consisted of evidence of progressive locally advanced or metastatic RAI-R DTC. All of the studies involved treatment with sorafenib in the Phase II or III setting. Phase I studies involving sorafenib were included if they were combination studies with another drug. All studies involved an intervention with sorafenib. Blinded and open-label randomized controlled studies (crossover permitted) and interventional single-arm open-label studies were included. Exclusionary criteria included a sample size under five (as in case series or reports), review papers, editorials, and preclinical in vitro studies or noninterventional studies. Observational cohort studies were included separately if they were conducted prospectively. Sorafenib combination studies (including Phase I studies) were included separately.

\section{Screening and data abstraction}

A two-level review process was implemented in order to obtain consensus among authors. Level 1 review by DM included all titles and abstracts based on exclusionary criteria. Full-text articles for all potentially relevant citations satisfying level 1 review were retrieved and were further reviewed by two researchers (DM, KJM). The titles and abstracts were then included if they met inclusionary criteria. Any uncertainty in level 2 screening was resolved by consensus among researchers (DM, KJM). Articles satisfying level 2 screening were included in the review.

Relevant citations were then evaluated by trial design, number of participants, subtype of thyroid carcinoma by histology, and dosage and schedule of sorafenib. Response 
data were subdivided by complete response (CR), PR, SD, progression-free survival (PFS), and overall survival (OS). Safety data were extracted by searching for types and rates of grade toxicity (grade $3-5$ especially noted), rates of dose reduction and discontinuation, and authors' discussion of side effect profile. Citations were evaluated for noteworthy clinical and laboratory observations.

\section{Results}

The systematic review strategy identified a total of 557 potentially relevant citations using PubMed and Embase on OvidSP. Figure 1 illustrates the search and screening process. PubMed revealed a total of 137 potentially relevant citations using the search terms "thyroid cancer" and "sorafenib", of which seven were included in the final review. Additionally, PubMed revealed a total of 125 potentially relevant citations using the search terms "thyroid tumor" and "sorafenib", of which ten were included in the final review. All PubMed citations were duplicated in the Ovid search, which captured all of the 557 potentially relevant citations. Citations were excluded if they included no original data, such as in the form of reviews (224 citations)

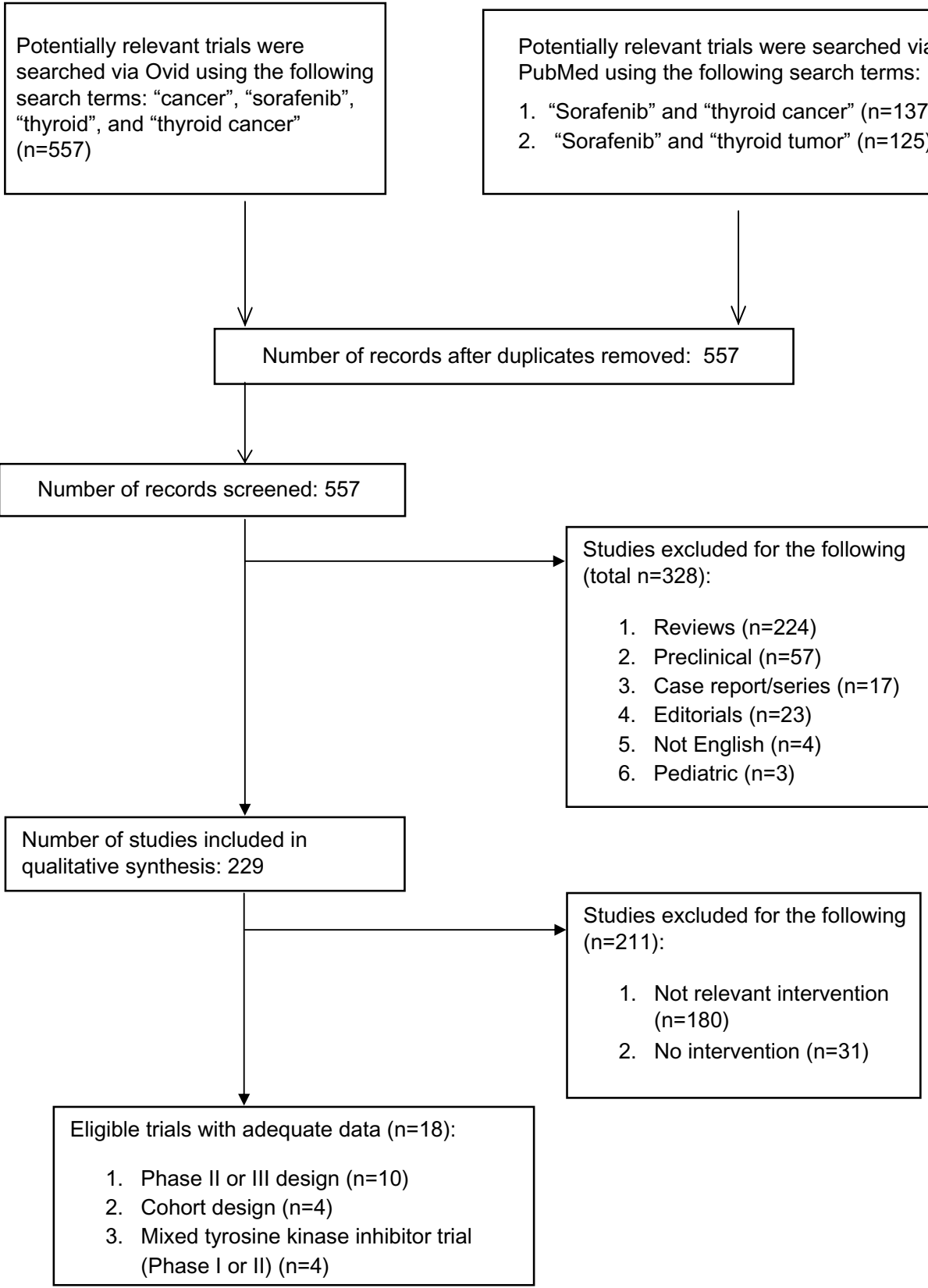

Figure I Consort diagram. 
or editorials (23 citations). Thirty-three citations were relevant but included no intervention. Other studies included an intervention but were not relevant for this review (180 citations). Fifty-seven citations were found to be nonclinical or preclinical work. Other studies met criteria for inclusion but were not published in English (four citations) or were relevant to pediatric population (three citations). The search uncovered ten relevant trials, four cohort observational studies, and four mixed TKI trials (included Phase I).

The findings highlight 18 trials extending from 2006 to 2013 (see Tables 1-3). All of the trials were conducted in North America (Canada or the United States), Europe, or the People's Republic of China and were collected among a predominately Caucasian population. All the trials were either single- or double-arm Phase II trials or a Phase III and Phase I/II trial in the combined sorafenib group. Trials included between nine and 417 participants with an average number of 51 participants per trial. This review evaluated a total of 864 participants. All of the studies included progressive locally advanced or metastatic RAI-R DTC, mostly of well-differentiated histology, with the exception of the study by Adili et al ${ }^{13}$ of exclusively poorly differentiated (PD) subtype of thyroid cancer. The studies varied in the subtypes of RAI-R DTC that were evaluated. Papillary thyroid cancer was the most common subtype followed by follicular thyroid cancer (FTC) and then subtypes of FTC (eg, Hürthle cell) and PD thyroid cancer. The Phase III Brose et $\mathrm{al}^{1}$ study evaluated $57 \%$ papillary thyroid cancer, $25 \%$ FTC, and 10\% PD (see Table 1). All of the studies used a sorafenib dose schedule of $400 \mathrm{mg}$ twice daily, with the exception of the Adili et $\mathrm{al}^{13}$ abstract, which did not include dose; the combination studies (Hong et al, ${ }^{14} \mathrm{Caba}$ nillas et $\mathrm{al}^{15}$ [see Table 3]); and the observational studies by de la Fouchardiere et al, ${ }^{16}$ which did not include dose, and Chen et al, ${ }^{17}$ which used $200 \mathrm{mg}$ twice daily (see Table 2). PR rates varied from $15 \%$ (Kloos et $\mathrm{al}^{18}$ ) to $38 \%$ (Keefe et $\mathrm{al}^{19}$ ), while SD rates varied from $34 \%$ (Hoftijzer et $\mathrm{al}^{20}$ ) to $68 \%$ (Ahmed et $\mathrm{al}^{21,22}$ ) in the Phase II setting. The Phase III study by Brose et al reported at ASCO 2013 revealed a PR of $12.2 \%$ versus $0.5 \%$ in the placebo group. ${ }^{1} \mathrm{OS}$ was not reached in the majority of studies but was recorded in the Keefe et al, ${ }^{19}$ Capdevila et al, ${ }^{23}$ and Schneider et al ${ }^{24}$ studies, in which the median OS (mOS) was 23.6, 35.3, and 34.5 months, respectively. The Brose et al Phase III randomized controlled trial met its primary endpoint with a median PFS (mPFS) of 10.8 months versus 5.8 months in the placebo group. ${ }^{1}$ mPFS in Phase II trials and observational studies varied from 6.7 months (de la Fouchardiere et $\mathrm{al}^{16}$ ) to 24 months (Keefe et $\mathrm{al}^{19}$ ). The average mPFS was 15.2 months including Phase III, Phase II, and observational studies and excluding the Adili et al ${ }^{13} 2013$ study of PD thyroid cancer. mPFS was not reported for the Marotta et $\mathrm{al}^{25} 2013$ and Ahmed et $\mathrm{al}^{21} 2008$ studies. The Adili et al 2013 Phase II case-control study of PD showed a clinically and statistically significant difference between sorafenib and placebo cohorts, including a PR difference of $23 \%$ versus $12.5 \%$ and $62 \%$ versus $50 \%$ SD in the placebo group. ${ }^{13} \mathrm{mPFS}$ and OS were, respectively, 9 and 24 months in the sorafenib group versus 3 and 9 months in the placebo group. ${ }^{13}$

The toxicity profile was significant most commonly for hand-foot syndrome (HFS), rash/desquamation, fatigue, alopecia, diarrhea, hypertension, arthralgia, bleeding, weight loss/anorexia, and fatigue. Grade $3 \mathrm{HFS}$ varied from $4 \%$ to $66 \%$. Grade 3 fatigue varied from $9 \%$ to $16 \%$. Grade 3 toxicities under 20\% included dermatologic issues (ie, desquamation) other than HFS, diarrhea, alopecia, hypertension, arthralgias, weight loss/anorexia, and fatigue. Clinically warranted dose reductions varied from $35 \%$ to $100 \%$. Discontinuation of sorafenib due to medication side effects varied from $0 \%$ to $20 \%$. Severe adverse events resulting in fatalities that were potentially due to sorafenib included death from bleeding complications and myocardial infarction (Marotta et $\mathrm{al}^{25}$ ).

Several studies noted adjustments made to thyroid hormone requirements with significant reductions with sorafenib (Chen et al, ${ }^{17}$ Kloos et al, ${ }^{18}$ Hoftijzer et al, ${ }^{20}$ Gupta-Abramson et $\left.\mathrm{al}^{26}\right)$. Several correlative studies reported BRAF and other mutational statuses of participants (Kloos et al, ${ }^{18}$ Brose et $\mathrm{al}^{27}$ ). Other correlative studies noted areas of specific responsiveness (de la Fouchardiere et al, ${ }^{16}$ Marotta et al, ${ }^{25}$ Cabanillas et $\mathrm{al}^{28}$ ) with most significant responses noted in lungs, lymph nodes, and liver lesions.

The systematic review uncovered four relevant sorafenib trials that evaluated its use in RAI-R DTC patients in combination with another targeted agent (see Table 3 ) such as tipifarnib (Hong et al, ${ }^{14}$ Cabanillas et $\mathrm{al}^{15}$ ), temsirolimus $\left(\right.$ Sherman et $\mathrm{al}^{29}$ ), and everolimus (Sherman et $\mathrm{al}^{30}$ ). Tipifarnib is a farnesyl transferase inhibitor, while temsirolimus is an intravenous inhibitor of mTOR and everolimus is an mTOR inhibitor given by mouth. The tipifarnib trials resulted in PR rates of $4.5 \%$ and $7 \%$, while SD was seen in $36 \%$ and $86 \% \cdot{ }^{14,15}$ mPFS was 18 months in the Hong et al 2011 study, but the analysis included MTC participants. ${ }^{14}$ Cabanillas et $\mathrm{al}^{15}$ reported that mOS was not reached but that OS was $79 \%$ at 24 months. ${ }^{15}$ Sorafenib/tipifarnib toxicity was mostly grade $1-2$, including rash, fatigue, and diarrhea, although the 

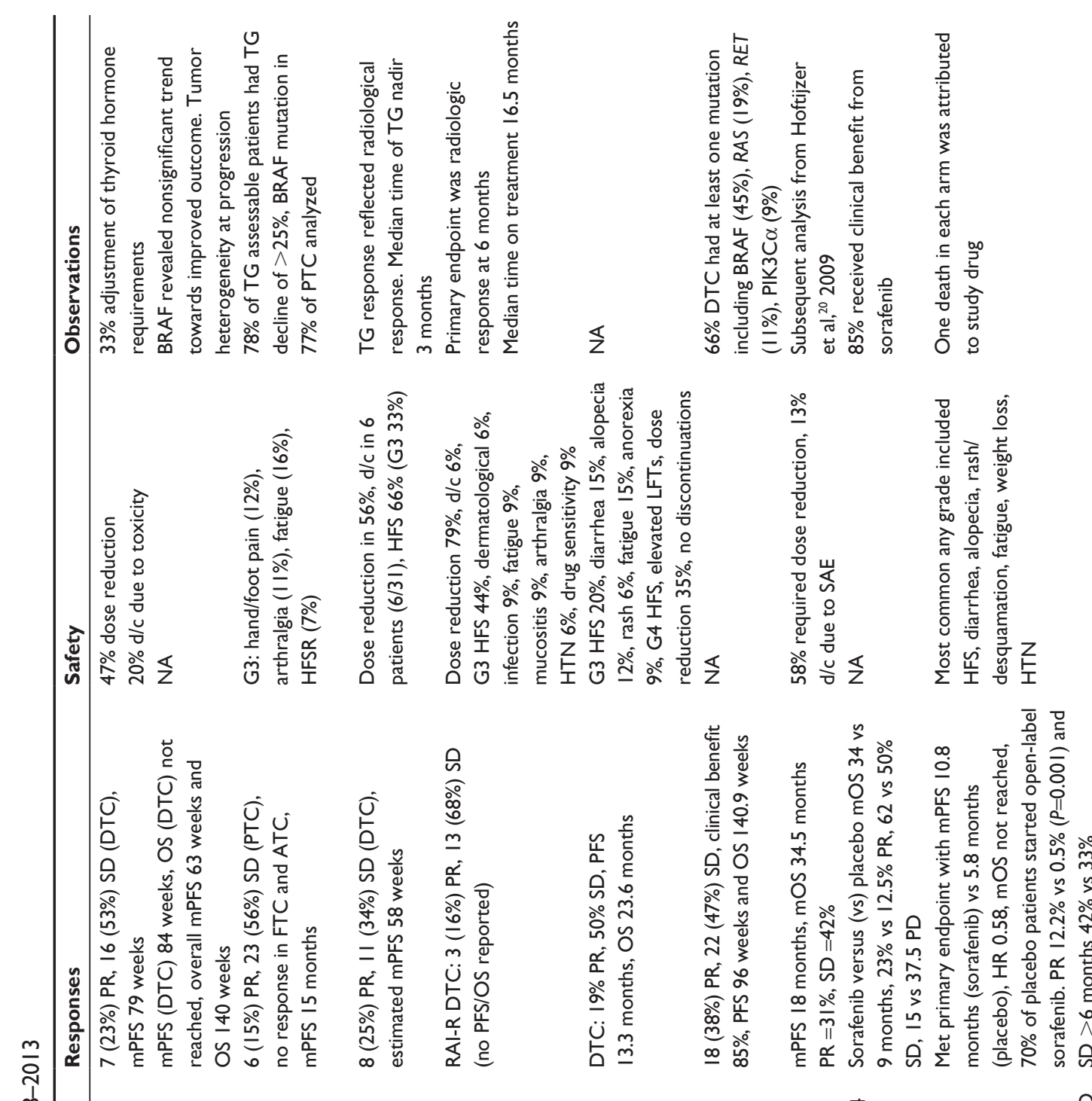

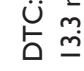

:

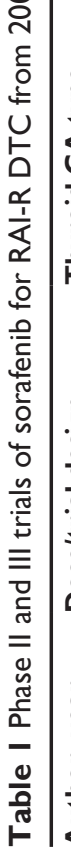

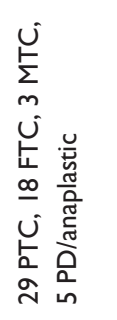

产

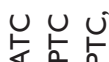

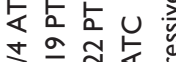

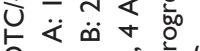

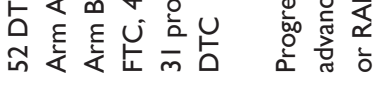

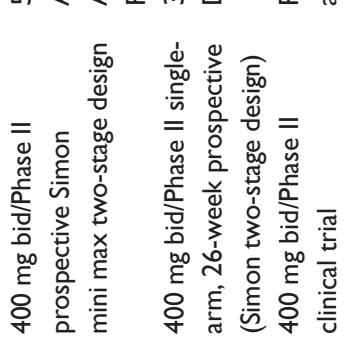

츨

$\circ$

$\sum^{2} \Sigma$

可

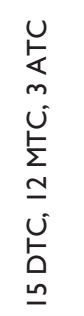
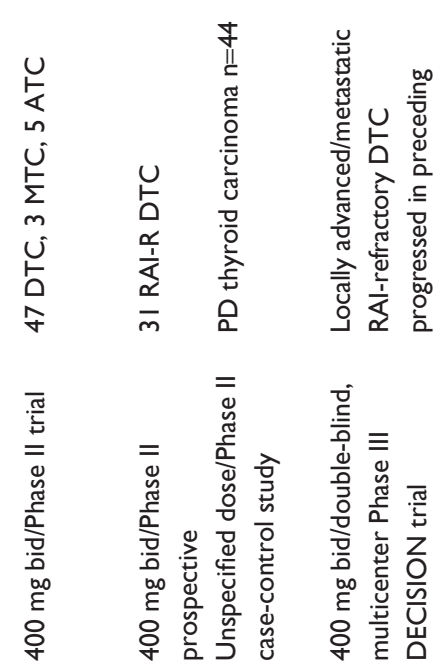

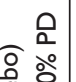

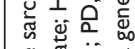

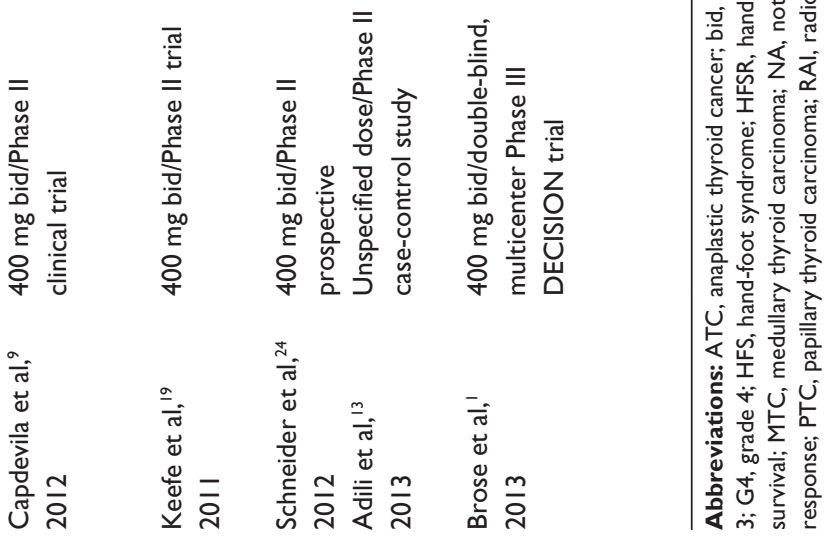


Table 2 Observational studies of sorafenib in RAI-R DTC from 2010-2013

\begin{tabular}{|c|c|c|c|c|c|}
\hline $\begin{array}{l}\text { Author, year of } \\
\text { observational study }\end{array}$ & $\begin{array}{l}\text { Thyroid CA - } \\
\text { inclusion criteria }\end{array}$ & $\begin{array}{l}\text { Drug } \\
\text { (intervention) }\end{array}$ & Responses & Safety & Observations \\
\hline Marotta et al, ${ }^{25} 2013$ & $\begin{array}{l}\text { Progressive RAI-R } \\
\text { DTC } n=17\end{array}$ & Sorafenib $400 \mathrm{mg}$ bid & $30 \% \mathrm{PR}, 4 \mathrm{I} \% \mathrm{SD}$ & $\begin{array}{l}\text { Three died } \\
\text { from bleeding } \\
\text { complications and } \\
\text { two died from } \\
\text { myocardial infarction }\end{array}$ & $\begin{array}{l}\text { Best response in LN and } \\
\text { lung lesions. Baseline TG } \\
\text { level and TG response } \\
\text { correlated to treatment } \\
\text { response }\end{array}$ \\
\hline $\begin{array}{l}\text { de la Fouchardiere } \\
\text { et al, }{ }^{16} 2013\end{array}$ & $\begin{array}{l}\text { Advanced RAI-R } \\
\text { DTC } n=45\end{array}$ & $\begin{array}{l}\text { Sorafenib } \\
\text { (unspecified dose) }\end{array}$ & $\begin{array}{l}\text { PR } 29 \%, \text { mPFS } \\
6.7 \text { months }\end{array}$ & NA & $\begin{array}{l}\text { Responsiveness: liver } \\
>\text { lung }>\text { lymph node } \\
>\text { bone }>\text { pleura }\end{array}$ \\
\hline Chen et al, ${ }^{17} 201 \mathrm{I}$ & RAI-R PTC $n=9$ & Sorafenib 200 mg bid & $\begin{array}{l}\text { PR } 33 \% \text {, SD } 44 \% \text {, } \\
\text { mPFS } 42 \text { weeks }\end{array}$ & NA & $\begin{array}{l}\text { Decreased serum TG by } \\
60 \% \text { within } 12 \text { weeks }\end{array}$ \\
\hline Cabanillas et al, ${ }^{28} 2010$ & $\begin{array}{l}\text { RAI-R DTC with } \\
\text { evidence of PD } \\
n=13\end{array}$ & Sorafenib $400 \mathrm{mg}$ & $\begin{array}{l}20 \% \text { PR, } 60 \% \text { SD, and } \\
20 \% \text { PD, clinical benefit } \\
80 \% \text {, mPFS } 19 \text { months, } \\
\text { mOS not reached }\end{array}$ & NA & $\begin{array}{l}\text { Responsiveness: } \\
\text { lung }(-22 \% \text { change })>L N \\
(0 \% \text { change })>\text { pleural } \\
\text { disease/bone }(\mathrm{PD})\end{array}$ \\
\hline
\end{tabular}

Abbreviations: bid, twice daily; CA, cancer; DTC, differentiated thyroid cancer; LN, lymph node; mPFS, median progression-free survival; mOS, median overall survival; NA, not applicable; PD, poorly differentiated thyroid carcinoma; PR, partial response; PTC, papillary thyroid carcinoma; RAI, radioactive iodine; SD, stable disease; TG, thyroglobulin.

Cabanillas et al 2010 study reported grade 3 rash in $11 \%$ of subjects. ${ }^{15}$ A sorafenib/mTOR combination study by Sherman et al in 2012 using intravenous temsirolimus found a 38\% PR in the recurrent RAI-R DTC thyroid cancer cohort that had not received previous systemic treatment. ${ }^{29}$ There was no correlation of response to either BRAF or RAS mutational status. ${ }^{29}$ Sherman et al then reported a sorafenib/everolimus combination two-stage prospective Phase II study in 2013 with 28 RAI-R DTC of various histological subtypes and found PR rates between $50 \%$ and $67 \%$ and SD rates between

Table 3 Combination studies of sorafenib and other targeted agents including the farnesyl transferase inhibitor tipifarnib; intravenous mTOR inhibitor temsirolimus, and the oral mTORinhibitor everolimus

\begin{tabular}{|c|c|c|c|c|}
\hline $\begin{array}{l}\text { Author, year of sorafenib/ } \\
\text { mixed TKI trial }\end{array}$ & Drug/trial design & Thyroid CA & Responses & Safety \\
\hline Cabanillas et al, ${ }^{15} 2010$ & $\begin{array}{l}\text { Sorafenib, tipifarnib/ } \\
\text { Phase I trial }\end{array}$ & $\begin{array}{l}22 \text { metastatic DTC } \\
\text { (I6 PTC, } 5 \text { FTC, I PD) }\end{array}$ & $\begin{array}{l}\text { Max tolerated dose: sorafenib } \\
600 \text { mg daily, tipifarnib } 200 \mathrm{mg} \text { daily } \\
\text { (split dosing), PR 7\%, } 86 \% \text { SD, } 7 \% \\
\text { PD, mOS not reached; however, } \\
\text { at } 24 \text { months, OS was } 79 \%\end{array}$ & $\begin{array}{l}\text { G3 rash in } 11 \% \text {, } \\
\text { GI-2 HFS } 37 \%, \\
\text { GI-2 rash } 43 \%\end{array}$ \\
\hline Hong et al, ${ }^{14} 201 \mathrm{I}$ & $\begin{array}{l}\text { Sorafenib } 400 \mathrm{mg} \text { qAM, } \\
\text { tipifarnib } 100 \mathrm{mg} \text { bid/ } \\
\text { Phase II prospective trial }\end{array}$ & $\begin{array}{l}\text { Metastatic DTC } \\
(\text { I } 6 \text { PTC, } 5 \text { FTC, } \\
\text { I PD) }\end{array}$ & $\begin{array}{l}\text { PR } 4.5 \% \text { and SD } 36 \% \text { at } 6 \text { months. } \\
\text { mPFS I } 8 \text { months (for all } \\
35 \text { patients including MTC) }\end{array}$ & $\begin{array}{l}\text { GI-2 toxicities } \\
\text { were rash, fatigue, } \\
\text { and diarrhea }\end{array}$ \\
\hline Sherman et al, ${ }^{29} 2012$ & $\begin{array}{l}\text { Sorafenib } 200 \mathrm{mg} \text { bid, } \\
\text { temsirolimus } 25 \mathrm{mg} \\
\text { weekly/single institution } \\
\text { Phase II prospective trial }\end{array}$ & $\begin{array}{l}\text { Progressive RAI recurrent/ } \\
\text { refractory non-medullary } \\
\text { DTC ( } 23 \text { PTC } \\
\text { I HTC } \\
5 \text { PD } \\
6 \text { ATC) } \\
-21 \text { prior systemic tx } \\
-6 \text { prior sorafenib }\end{array}$ & $\begin{array}{l}\text { PR } 38 \% \text { in previously untreated } \\
\text { group. No correlation of } \\
\text { response to either BRAF or } \\
\text { RAS mutational status }\end{array}$ & NA \\
\hline Sherman et al, ${ }^{30} 2013$ & $\begin{array}{l}\text { Sorafenib } 400 \mathrm{mg} \\
\text { bid, everolimus } 5 \mathrm{mg} \\
\text { daily/two-stage Phase II } \\
\text { prospective trial }\end{array}$ & $\begin{array}{l}8 \text { PTC, } 9 \text { Hürthle, } \\
2 \text { FTC, } 8 \text { PD, } 9 \text { MTC }\end{array}$ & $\begin{array}{l}\quad \text { PR SD } \\
\text { PTC: } 50 \% 38 \% \\
\text { HTC: } 67 \% 33 \% \\
\text { FTC: } 50 \% 50 \% \\
\text { PD: } 50 \% 50 \% \\
\text { MTC: } 44 \% 44 \% \\
\text { Total: } 53 \% 42 \%\end{array}$ & $\begin{array}{l}\text { G4-5: } \\
\text { I transaminitis, } \\
\text { I hyperglycemia, } \\
\text { I pancreatitis }\end{array}$ \\
\hline
\end{tabular}

Abbreviations: ATC, anaplastic thyroid cancer; bid, twice daily; BRAF, V-raf murine sarcoma viral oncogene homolog BI; CA, cancer; CR, complete response; DTC, differentiated thyroid cancer; FTC, follicular thyroid carcinoma; GI-2, grade I to 2; G3, grade 3; G4-5, grade 4 to 5; HTC, Hürthle cell thyroid carcinoma; mOS, median overall survival; mPFS, median progression-free survival; MTC, medullary thyroid carcinoma; mTOR, mammalian target of rapamycin; NA, not applicable; OS, overall survival; PD, poorly differentiated thyroid carcinoma; PR, partial response; PTC, papillary thyroid carcinoma; qAM, every morning; RAI, radioactive iodine; RAS, rat sarcoma gene; SD, stable disease; TG, thyroglobulin; TKI, tyrosine kinase inhibitor; tx, prior treatment. 
$33 \%$ and $50 \%{ }^{30}$ Cumulative grade 4 toxicities were seen in the form of one case each of hyperglycemia, pancreatitis, and transaminitis.

\section{Discussion}

This review highlights clinically relevant Phase I- to III-level data supporting the use of sorafenib in RAI-R DTC. A range of PR among the non-combination trials was observed, from $15 \%$ to $38 \%$, and SD varied from $33 \%$ to $68 \%$. Although there is variability in their ranges, there is a consistently observed PR and SD in this population with a significant but clinically acceptable toxicity profile that is similar to the toxicity profile in hepatocellular carcinoma and renal cell carcinoma. ${ }^{30,31}$ Thus, these data support its use as a preferred first-line therapeutic agent over the historically used doxorubicin or other cytotoxic chemotherapy. This is a major stride and clearly represents the newest therapeutic modality that is now the standard of care for RAI-R DTC. ${ }^{32}$

The next most logical future direction would certainly be to achieve a greater or more durable response, perhaps by utilizing combined mechanisms/modalities without creating additive toxicity. The rationale for targeted therapy in thyroid cancer is to suppress activation of mitogenic and angiogenic signaling pathways known to occur in both hereditary and sporadic thyroid cancers. ${ }^{9}$ The more aggressive dedifferentiated forms contain increasingly more activating mutations in RAS, PTEN, PI3K, and BRAF ${ }^{\mathrm{V} 600 \mathrm{E}} .4$ To that end, this review also includes the most recent work in combined modality therapy looking at four prospective trials from 2010 to 2013. . $^{14,15,29,30}$ The sorafenib plus tipifarnib Phase I trial ${ }^{15}$ only achieved a PR of $7 \%$ but showed SD for $86 \%$ of the 22 patients. However, the Phase II trial achieved a similar PR of $4.5 \%$ and a lower SD of $36 \%$ at 6 months, which is not improved over sorafenib alone. The Sherman et al 2012 study of sorafenib plus temsirolimus intravenous given weekly achieved a PR of $38 \%$ in the previously untreated group and showed no correlation with RAS or BRAF status. ${ }^{29}$ The Sherman et al 2013 study of sorafenib plus daily oral everolimus achieved a remarkable PR of 50\%-67\% among subtypes of RAI-R DTC with limited grade 4 toxicity. ${ }^{30}$ The question of sorafenib combination studies, in particular with mTOR inhibitors, deserves to be more thoroughly investigated.

Two additional reviews highlight many of the same studies that were evaluated in this review. First, Anderson et al searched for relevant TKI classes (of drugs) that have been studied in the treatment of RAI-R DTC. Their review included five unique sorafenib monotherapy trials and one combination therapy trial with temsirolimus. ${ }^{33}$ They found the same range of PR (from $13 \%$, in those patients who had received prior chemotherapy, to $38 \%$ in chemotherapynaive patients) and no CRs. All the trials in their review were included in this review. ${ }^{18-21,26,33}$ The mPFS was up to 96 weeks and mOS up to 161 weeks. They found that the rates of sorafenib discontinuation were between $6 \%$ and $25 \%$ due to side effects. Secondly, Shen et al reported a meta-analysis of sorafenib use in RAI-R DTC that included seven trials from 2008 to 2013 that were all included in this review. They found a PR of $15 \%-33 \%$ with no CR and SD from $41 \%-82 \%$. PFS varied from 4.5 to 19.6 months and OS varied from 10 to 37.5 months. ${ }^{34}$

Aside from including relevant combination trials that show promising synergistic effects between sorafenib and mTOR inhibitors, this systematic review included 18 trials (as opposed to five trials per the Anderson et $\mathrm{al}^{33}$ and seven trials per the Shen et $\mathrm{al}^{34}$ reviews). We included observational trials that were listed separately (see Table 2), the results of which were consistent with other prospective trials but may have included extra valuable information (de la Fouchardiere et al, ${ }^{16}$ Chen et al, ${ }^{17}$ Marotta et al, ${ }^{25}$ Cabanillas et $\mathrm{al}^{28}$ ). For example, these trials include observed anatomic areas of sorafenib responsiveness and measurements of thyroglobulin. This systematic review also included one of the few available trials of exclusively PD thyroid cancers which are usually included amongst other histological thyroid cancer subtypes. The Adili et al 2013 Phase II case-control study included 44 PD thyroid carcinoma patients and found that sorafenib provided a therapeutic benefit manifested as an OS of 34 months versus 9 months. ${ }^{13}$ This suggests that sorafenib is able to halt progression in more aggressive forms of RAI-R DTC.

There are several important limitations to this systematic review of treatment of locally advanced or metastatic RAIresistant well-DTC. Although sorafenib was FDA approved for this indication as of November 22, 2013, the DECISION Phase III trial has only been presented in abstract form by Brose et al at ASCO in June 2013 and has not yet undergone a peer-reviewed publication review. ${ }^{1}$ Therefore, the majority of supportive data are derived from nonrandomized Phase II trials that had variable stringency in assessing "progressive" RAI-R DTC disease and could perhaps overestimate the effects of sorafenib. Although the inclusion criteria of the majority of studies stated the necessity for progression of disease, the time course for when a participant was progressing was not controlled (ie, after 1 year or 10 years), which highlights differences in tumor biology and disease aggressiveness. Also, studies had a variable amount of disease tumor burden and did not control for whether participants 
had had previous chemotherapy or biological therapy such as a TKI. Additionally, our understanding of disease control with sorafenib is limited by the variable amount of focus on durability or response, as PFS and OS were only reported in select studies.

Studies have not provided a clear indication as to when there is a clear indication to start therapy within the disease trajectory. Future Phase II or III trial inclusion criteria should precisely indicate a defined point of disease progression at which to start targeted therapy. This would provide clinically meaningful data that can be extrapolated for starting therapy.

\section{Conclusion}

Historically, RAI-R DTC has had a relatively dismal prognosis in comparison to other thyroid cancer types with no true standard of care. Although the data are based primarily on nonrandomized Phase II trials and on only one randomized Phase III trial, it has been shown convincingly that sorafenib slows the progression of disease in the majority of cases. Current investigations should aim toward improving efficacy utilizing the targeted therapy model, perhaps with combined modalities such as sorafenib and an mTOR inhibitor, in the randomized setting while continuing to seek out effective agents with less toxicity.

\section{Disclosure}

The authors report no conflicts of interest in this work.

\section{References}

1. Brose MS, Nutting C, Jarzab B, et al. Sorafenib in locally advanced or metastatic patients with radioactive iodine-refractory differentiated thyroid cancer: the Phase III DECISION trial. J Clin Oncol. 2013; 31(suppl; abstr 4a).

2. Durante C, Haddy N, Baudin E, et al. Long-term outcome of 444 patients with distant metastasis from papillary and follicular thyroid carcinoma: benefits and limits of radioiodine therapy. J Clin Endocrinol Metab. 2006;91:2892-2899.

3. Nikiforov Y, Nikiforova M. Molecular genetics and diagnosis of thyroid cancer. Nat Rev Endocrinol. 2011;7:569-580.

4. SEER Stat Fact Sheets: Thyroid Cancer [webpage on the Internet]. National Cancer Institute; 2011. Available from:http://seer.cancer.gov/ statfacts/html/thyro.html\#incidence-mortality. Accessed.

5. Schlumberger M, Tubiana M, De Vathaire F, et al. Long-term results of treatment of 283 patients with lung and bone metastases from differentiated thyroid carcinoma. J Clin Endocrinol Metab. 1986;63:960-967.

6. Capdevila J, Argiles G, Rodriguez-Frexinos V, NuñezI, Tabernero J. New approaches in the management of radioiodine-refractory thyroid cancer: the molecular targeted therapy era. Discov Med. 2010;9: 153-162.

7. Brose MS, Smit J, Capdevila J, et al. Regional approaches to the management of patients with advanced, radioactive iodine-refractory differentiated thyroid carcinoma. Expert Rev Anticancer Ther. 2012;12(9):1137-1147.

8. Gild M, Bullock M, Robinson BG, Clifton-Bligh R. Multikinase inhibitors: a new option for the treatment of thyroid cancer. Nat Rev Endocrinol. 2011;7:617-624.
9. Capdevila J, Iglesias L, Halperin I, et al. Sorafenib in metastatic thyroid cancer. Endocr Relat Cancer. 2012;19:209-216.

10. Wilhelm S, Carter C, Lynch M, et al. Discovery and development of sorafenib: a multikinase inhibitor for treating cancer. Nat Rev Drug Discov. 2006;5(30):835-844.

11. Wells SA, Robinson BG, Gagel RF, et al. Vandetanib in patients with locally advanced or metastatic medullary thyroid cancer: a randomized, double-blind phase III trial. J Clin Oncol. 2012;30(2):134-141.

12. Elisei R, Schlumberger MJ, Muller SP, et al. Cabozantinib in progressive medullary thyroid cancer. J Clin Oncol. 2013;31(29):3639-3646.

13. Adili A, Chasen B, Dadu R, et al. Outcomes of patients with poorly differentiated thyroid cancer of follicular origin treated with first line sorafenib (abstract oral 96). American Thyroid Association. 2013;(Suppl A-47).

14. Hong DS, Cabanillas ME, Wheler J, et al. Inhibition of the Ras/Raf/ MEK/ERK and RET kinase pathways with the combination of the multikinase inhibitor sorafenib and the farnesyltransferase inhibitor tipifarnib in medullary and differentiated thyroid malignancies. J Clin Endocrinol Metab. 2011;96(4):997-1005.

15. Cabanillas ME, Kurzrock R, Sherman SI, et al. Phase I trial of combination sorafenib and tipifarnib: the experience of advanced differentiated thyroid cancer (DTC) and medullary thyroid cancer (MTC) (abstract 5586). J Clin Oncol. 2010;28(Suppl 15: S5586).

16. de la Fouchardiere, Massicotte MH, Borget I, et al. Sequential TKI treatments for iodine-refractory differentiated thyroid carcinomas (abstract 6092). J Clin Oncol. 2013;31(Suppl 15: S6092).

17. Chen L, Shen Y, Lou Q, Yu Y, Lu H, Zhu R. Response to sorafenib at a low dose in patients with radioiodine-refractory pulmonary metastases from papillary thyroid carcinoma. Thyroid. 2011;21:119-124.

18. Kloos RT, Ringel MD, Knopp MV, et al. Phase II trial of sorafenib in metastatic thyroid cancer. J Clin Oncol. 2009;27(10):1675-1684.

19. Keefe S, Troxel A, Rhee S, et al. Phase II trial of sorafenib in patients with advanced thyroid cancer. J Clin Oncol. 2011;29(Suppl; abstr 5562 ).

20. Hoftijzer H, Heemstra KA, Morreau H, et al. Beneficial effects of sorafenib on tumor progression, but not on radioiodine uptake in patients with differentiated thyroid carcinoma. Eur J Endocrinol. 2009;161: 923-931.

21. Ahmed M, Barbachano Y, Riddell A, et al. Analysis of the efficacy and toxicity of sorafenib in thyroid cancer: a phase II study in a UK based population. Eur J Endocrinol. 2011;185:315-322.

22. Ahmed M, Barbachano Y, Riddell AM, et al. An open label phase II study evaluating the safety and efficacy of sorafenib in metastatic advanced thyroid cancer. Ann Oncol. 2008;19(Suppl 8: A691PD).

23. Capdevila J, Iglesias L, Halperin I, et al. Sorafenib in patients (pts) with advanced thyroid carcinoma (TC): a compassionate use program [abstract no 5590]. J Clin Oncol. 2010;28(Suppl 15: A5590).

24. Schneider TC, Abdulrahman RM, Corssmit EP, Morreau H, Smit JW, Kapiteijn E. Long term analysis of the efficacy and tolerability of sorafenib in advanced radio-iodine refractory differentiated thyroid carcinoma: final results of a phase II trial. Eur J Endocrinol. 2012;167: 643-650.

25. Marotta V, Ramundo V, Camera L, et al. Sorafenib in advanced iodinerefractory differentiated thyroid cancer: efficacy, safety and exploratory analysis of role of serum thyroglobulin and FDG-PET. Clin Endocrinol (Oxf). 2013;78:760-767.

26. Gupta-Abramson V, Troxel AB, Nellore A, et al. Phase II trial of sorafenib in advanced thyroid cancer. $J$ Clin Oncol. 2008;26:4714-4719.

27. Brose M, Troxel A, Redlinger M, et al. Effect of $B R A F^{\mathrm{V} 600 \mathrm{E}}$ on response to sorafenib in advanced thyroid cancer patients. J Clin Oncol. 2009; 23(Suppl 15; abstr 6002).

28. Cabanillas M, Waquespack S, Bronstein Y, et al. Treatment with tyrosine kinase inhibitors for patients with differentiated thyroid cancer: the MD Anderson experience. J Clin Endocrinol Metab. 2010;95:2588-2595.

29. Sherman EJ, Ho AL, Fury MG, et al. A phase II study of temsirolimus/ sorafenib in patients with radioactive iodine (RAI)-refractory thyroid carcinoma. J Clin Oncol. 2012;29(Suppl: A5514). 
30. Sherman EJ, Ho AL, Fury MG, et al. Phase II study of everolimus and sorafenib for the treatment of metastatic thyroid cancer. J Clin Oncol. 2013;31(suppl; abstr 6024).

31. Strumberg D. Sorafenib for the treatment of renal cancer. Expert Opin Pharmacother. 2012;13(3):407-419.

32. Thyroid Cancer (Version 2 2013). Fort Washington, PA: National Comprehensive Cancer Network; 2013. Available from: http://www nccn.org/professionals/physician_gls/pdf/thyroid.pdf. Accessed March 23, 2014.
33. Anderson RT, Linnehan JE, Tongbram V, Keating K, Wirth LJ. Clinical, safety, and economic evidence in radioactive iodine-refractory differentiated thyroid cancer: a systematic literature review. Thyroid. 2013;23(4):392-407.

34. Shen CT, Qui ZL, Luo QY. Sorafenib in the treatment of radioiodinerefractory differentiated thyroid cancer: a meta-analysis. Endocr Relat Cancer. 2014;27(2):253-261.

\section{Publish your work in this journal}

OncoTargets and Therapy is an international, peer-reviewed, open access journal focusing on the pathological basis of all cancers, potential targets for therapy and treatment protocols employed to improve the management of cancer patients. The journal also focuses on the impact of management programs and new therapeutic agents and protocols on

\section{Dovepress}

patient perspectives such as quality of life, adherence and satisfaction. The manuscript management system is completely online and includes a very quick and fair peer-review system, which is all easy to use. Visit http://www.dovepress.com/testimonials.php to read real quotes from published authors.

Submit your manuscript here: http://www.dovepress.com/oncotargets-and-therapy-journal 